\title{
"Blue button" access to medical records
}

Published at www.cmaj.ca on Sept. 28

$\mathrm{F}$ or many Americans, the ability to download their electronic health information is becoming just a click of a "blue button" away.

The United States Centers of Medicare \& Medicaid Services is developing a blue button icon for its MyMedicare.gov website to readily allow beneficiaries to securely access and download electronic claims and medical information.

The blue button feature will allow registered MyMedicare .gov users to safely download a data file of their claims data, their self-entered data, or both, writes Centers of Medicare \& Medicaid Services press officer Joseph Kuchler in an email. Beneficiaries will then be able to manage and share that information using the personal health application of their choice, such as Google Health.

A similar feature was introduced on the MyHealtheVet website by the US Veterans Administration earlier in September. By clicking on a blue button icon, veterans can view, print and download self-entered medical data and their electronic health records at the Veterans Administration. The feature will be extended to a whole network of health sites that veterans might use.

Previously, Medicare beneficiaries could access and add to their claims data on MyMedicare.gov, and could print an On-the-Go report to share with their health care providers. But they couldn't download the same data to store on their computer or integrate with other personal health records.

Both the Medicare and veterans blue button projects are being developed in partnership with the US Defense

Department and the not-for-profit Markle Foundation, a New York City, New York-based organization that promotes the use of information technologies to resolve health care and national security needs.

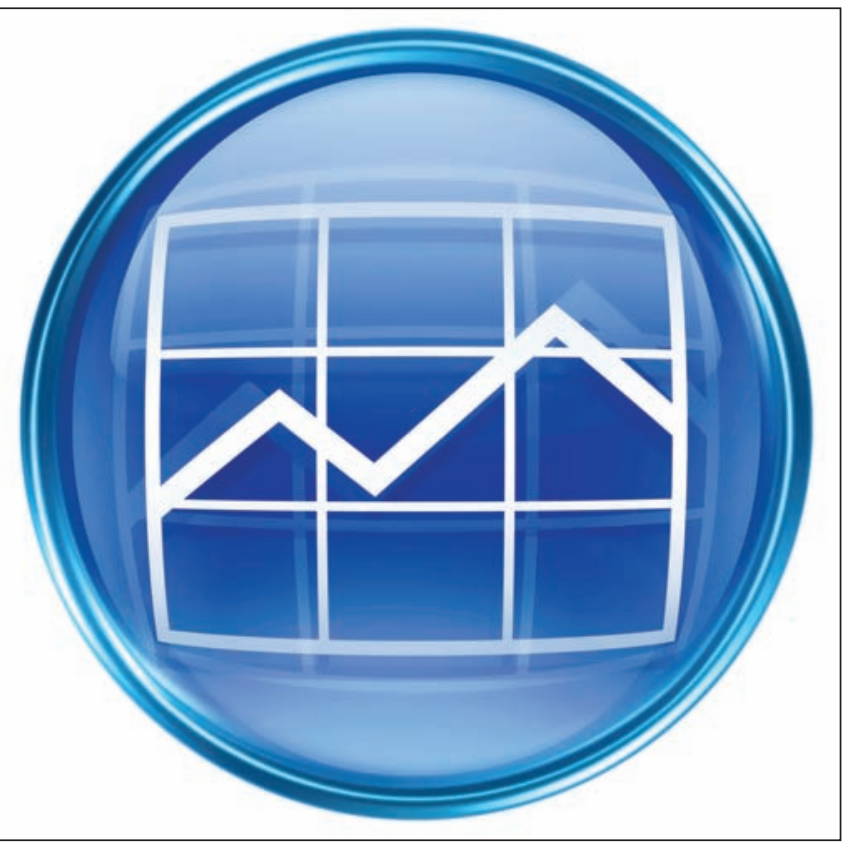

By simply clicking on a blue button icon, users will be able to download their medical data to store on their personal computers.

across labs, pharmacies, hospitals and primary care providers, so they'll seek out services and applications that will help organize their health information."

For the average person who may not pay much attention to their cholesterol levels, for example, "think of the benefit of having an automatically generated graph to show you how it's been trending," Diamond says. "Having that kind of information will certainly prompt patients to talk to their health care providers about issues they otherwise might not have noticed."

But with ease of access come concerns about safety and privacy protection.

Sound authentication, specific language reminding users not to download or store their personal health information on shared computers, and providing a clear explanation of the download function and its security implications are among the safeguards urged by the foundation (www.markle.org /downloadable_assets/2010 0831_dlcapability.pdf).

Despite those cautionary notes, the

"We live in a networked world and no one thinks twice about going online to manage finances, or travel plans, or taxes. This is about building an expectation that health information should be equally accessible," says Dr. Carol Diamond, managing director of Markle's health care program. "It's also about reducing the amount of information that slips through the cracks in our health care system, such as when tests get repeated because a result isn't available."

Highlighting those cracks may also lead to better self-management by patients, she says. "It's going to become apparent their health information is scattered, not just across providers, but foundation recommended in its paper, The Download Capability, that a blue button feature be widely implemented. The proposal has gained support from 46 insurers, provider groups, consumer advocates and technology companies, including industry giants Microsoft and Google.

"The first step is just enabling people to download their inform.ation," says Diamond. "The more this becomes available the more a demand for standardization and additional features will grow." — Lauren Vogel, CMAJ

DOI:10.1503/cmaj.109-3685 